\title{
Clinical and Serological Assessment of Children Exposed in Utero to Confirmed Maternal Rubella
}

\author{
CATHERINE S. PECKHAM
}

British Medical fournal, 1974, 1, 259-261

\section{Summary}

As a result of the work of the Public Health Laboratory Service Working Party on Rubella (1970) it was possible to examine the children of 60 susceptible women who were in contact with rubella during their pregnancy and who subsequently showed serological evidence of the infection, despite immunoglobulin prophylaxis. When the children were assessed between 8 months and 4 years 8 months of age a blood sample was also taken and tested for rubella antibodies so that a retrospective diagnosis of congenital rubella infection could be made. Only $19 \%$ of children exposed to subclinical maternal rubella showed evidence of intrauterine infection compared with $53 \%$ of those born to mothers who had clinical rubella. One of the 26 children exposed to subclinical maternal infection had a rubella defect, compared with 9 of the 34 children exposed to clinical maternal rubella.

\section{Introduction}

Rubella vaccination seems to be the most likely method of preventing fetal abnormalities resulting from rubella infection in early pregnancy but it will be some years before the full impact of rubella vaccination becomes apparent. Until then immunoglobulin will continue to play a part in the management of women who come into contact with rubella during pregnancy. It is important therefore to determine whether immunoglobulin given to pregnant women in contact with rubella prevents fetal defect. The efficacy of immunoglobulin in preventing rubella infection has long been open to controversy but there has been little opportunity to assess its affect on children born after proved exposure in utero to maternal rubella occurring in spite

\footnotetext{
Department of Microbiology, Hospital for Sick Children, and Institute of Child Health, London

CATHERINE S. PECKHAM, M.B., B.S., M.R.C., Research Fellow
}

of the administration of immunoglobulin. A prospective assessment of this problem is essential.

The Public Health Laboratory Service (P.H.L.S.) Working Party on Rubella (1970) carried out studies on several thousand pregnant women given immunoglobulin after exposure to rubella and 652 adult women similarly at risk but not pregnant. The working party concluded on the basis of their clinical and laboratory findings that "whether judged on the serological evidence alone, or as a result of exposure to a confirmed index case, immunoglobulin in the amounts given did not appear to affect the incidence of rubella by comparison with the uninoculated group. Suppression of clinical manifestations attributable to immunoglobulin was possible in a few instances, but this could also have been an example of natural variation."

The present paper reports the clinical and serological findings in 60 children born to mothers who after exposure to rubella in pregnancy and serological evidence of infection despite the administration of immunoglobulin had decided to go to term.

\section{Patients and Methods}

As a result of the P.H.L.S. working party's investigation of the role of immunoglobulin in the prevention of rubella in pregnancy 60 children ( 33 boys and 27 girls) whose mothers had contracted rubella in pregnancy, with or without clinical manifestations of the infection, were traced and examined when they were between 8 months and 4 years 8 months of age (78\% were under 3 years of age).

Maternal rubella had been diagnosed by either neutralization or rubella haemagglutination inhibition (H.I.) antibody tests which were carried out at P.H.L.S. laboratories throughout Britain. A serum sample was taken from the mother after contact with rubella and before the administration of immunoglobulin. This sample was tested for the presence of rubella antibody and if none was detected-that is, if the mother was seronegative and therefore susceptible to rubella-a further blood sample was taken about six weeks later and tested. Acquisition of antibody as determined by the antibody tests on these two samples was taken to indicate that rubella infection had occurred in spite of the administration of immunoglobulin.

Some three-quarters of the children were examined personally at the Hospital for Sick Children, London, but those who lived 
too far away were seen by local paediatricians, who completed a standard examination form. The examination procedure was similar to that previously described (Peckham, 1972) and included a detailed history obtained from the mother, a full examination, and developmental assessment with special emphasis on hearing and language. A serum sample was collected at the time of the examination and tested for rubella H.I. antibody (Marshall et al., 1971). In nine children where it was not possible to obtain a serum sample a capillary blood sample was collected from a finger prick on to absorbent filter paper and tested for rubella H.I. antibody using the method previously described (Dudgeon et al., 1971). Of these nine children seven were over 4 years of age, one was 3 years of age, and one was 22 months.

\section{Results}

Altogether 34 of the children examined had been exposed to serologically confirmed rubella which occurred with a rash or illness compatible with rubella (clinical rubella) and 26 had been exposed to maternal rubella which had been diagnosed from serological findings only, there being no illness after the rubella contact (subclinical rubella). Of the 34 children exposed to clinical rubella $18(53 \%$ ) were found to have rubella antibodies (seropositive group) whereas 16 were not (seronegative group). Of the 26 children who had been exposed to subclinical maternal infection, however, only five (19\%) were seropositive (table I).

The presence of rubella H.I. antibody in the child was used to make a retrospective diagnosis of intrauterine infection. Maternal antibodies in the child have usually declined by 6 months of age and postnatal infection is unusual before 4 years of age. The age of the child at the time of his or her serological assessment is therefore of great importance (table II).

TABLE I-Serological Findings in 60 Children aged 8 Months to 4 Years 8 Months born to Mothers with Confirmed Rubella after Administration of Immunoglobulin

\begin{tabular}{|c|c|c|c|c|c|c|c|}
\hline \multirow{3}{*}{\multicolumn{2}{|c|}{ Maternal Rubella }} & \multicolumn{4}{|c|}{ Serological Status } & \multirow{2}{*}{\multicolumn{2}{|c|}{ Total }} \\
\hline & & \multicolumn{2}{|c|}{ Seropositive } & \multicolumn{2}{|c|}{ Seronegative } & & \\
\hline & & No. & $\%$ & No. & $\%$ & No. & $\%$ \\
\hline $\begin{array}{l}\text { Clinical } \\
\text { Subclinical }\end{array}$ & $\begin{array}{ll} & \\
\cdots & \end{array}$ & $\begin{array}{r}18 \\
5\end{array}$ & $\begin{array}{l}53 \\
19\end{array}$ & $\begin{array}{l}16 \\
21\end{array}$ & $\begin{array}{l}47 \\
81\end{array}$ & $\begin{array}{l}34 \\
26\end{array}$ & $\begin{array}{l}100 \\
100\end{array}$ \\
\hline \multicolumn{2}{|c|}{ Total } & 23 & 38 & 37 & 62 & 60 & 100 \\
\hline
\end{tabular}

TABLE II-Serological Status of Child in Relation to Age at Examination. Results expressed as Number of Children with H.I. Antibody/Number of Children examined

\begin{tabular}{|c|c|c|c|c|c|c|c|c|}
\hline \multicolumn{3}{|c|}{ Maternal Rubella } & \multirow{2}{*}{$\begin{array}{c}\begin{array}{c}6-11 \\
\text { Months }\end{array} \\
3 / 4 \\
0 / 2\end{array}$} & \multirow{2}{*}{$\begin{array}{c}1 \text { Year } \\
\begin{array}{r}10 / 22 \\
1 / 11\end{array}\end{array}$} & \multirow{2}{*}{$\begin{array}{c}2 \text { Years } \\
3 / 4 \\
0 / 4\end{array}$} & \multirow{2}{*}{$\begin{array}{c}3 \text { Years } \\
1 / 2 \\
1 / 3\end{array}$} & \multirow{2}{*}{$\begin{array}{c}4 \text { Years } \\
\begin{array}{c}1 / 2 \\
3 / 6\end{array}\end{array}$} & \multirow{2}{*}{$\begin{array}{r}\text { Total } \\
18 / 34 \\
5 / 26\end{array}$} \\
\hline $\begin{array}{l}\text { Clinical } \\
\text { Subclinical }\end{array}$ & $\because$ & 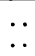 & & & & & & \\
\hline \multicolumn{3}{|c|}{ Total } & \multicolumn{3}{|c|}{$17 / 47$} & \multicolumn{2}{|c|}{$6 / 13$} & $23 / 60$ \\
\hline
\end{tabular}

Under the age of 3 years just over half of the children exposed to clinical rubella were seropositive as compared with only one of the 17 children exposed to subclinical infection. The mother of the latter child, however, was West Indian and it is possible that a rash could have passed unnoticed. Only four children exposed to clinical rubella were examined after their third birthday and two of these were seropositive. More children exposed to subclinical rubella were examined after the age of 3 years, six of them after their fourth birthday. As serological results are less reliable at this age the presence of rubella antibody in this group could have been due to postnatally acquired infection, and less reliance can be placed on the serological findings. The explanation for the difference in age between the two groups at the time of examination was that mothers who had normal children and had experienced no illness during pregnancy were unaware that their children were "at risk" and were reluctant to bring them to be examined.

Of the 34 children exposed to clinical infection $9(27 \%)$ had defects compatible with rubella (table III). These included six cases of bilateral perceptive deafness-one associated with mental retardation-and three of speech delay. One of the children with delayed speech was below the 10th centile for height and weight and at 2 years 11 months was unable to say any words though hearing was satisfactory. All but one of the children with defects were seropositive (table III). The seronegative child, aged 3 years, presented with a delay in speech All the children with defects had been exposed to maternal rubella in the first 16 weeks of pregnancy.

TABLE III-Clinical and Serological Findings in 34 Children born to Mothers with Clinical Rubella confirmed by Serology

\begin{tabular}{|c|c|c|c|c|c|c|c|}
\hline \multirow{2}{*}{\multicolumn{3}{|c|}{$\begin{array}{l}\text { Serological Status } \\
\text { of Children }\end{array}$}} & \multicolumn{4}{|c|}{ Week of Maternal Rash } & \multirow{2}{*}{$\begin{array}{l}\text { Total No. } \\
\text { of Children }\end{array}$} \\
\hline & & & $\leqslant 8$ & $9-12$ & $13-16$ & $\geqslant 17$ & \\
\hline $\begin{array}{l}\text { Seropositive: } \\
\text { Rubella defect } \\
\text { No defect } \\
\text { Seronegative: } \\
\text { Rubella defect } \\
\text { No defect }\end{array}$ & $\begin{array}{l}\ldots \\
\cdots \\
\cdots\end{array}$ & $\begin{array}{c}. \\
. \\
.\end{array}$ & 1 & $\begin{array}{l}5 \\
2\end{array}$ & $\begin{array}{l}2 \\
4 \\
1 \\
4\end{array}$ & 4 & $\left.\begin{array}{r}8 \\
10\end{array}\right\} 18$ \\
\hline Total & & & 1 & 13 & 11 & 9 & 34 \\
\hline
\end{tabular}

Only one of the 26 children exposed to subclinical maternal rubella had a defect. This was a seropositive child who was examined at the age of 3 years 10 months and found to have bilateral perceptive deafness.

It was, of course, impossible to time the week of pregnancy at which infection occurred in those mothers who remained asymptomatic but the distribution would probably have been similar to that group with clinical manifestations, as the original contact occurred at similar stages in pregnancy.

\section{Discussion}

The P.H.L.S. Working Party on Rubella (1970) concluded that immunoglobulin gave little protection against maternal rubella in susceptible women. Before finally concluding that immunoglobulin is ineffective in the prevention of fetal defects resulting from maternal rubella, however, it seemed essential to follow up the offspring of women who went on to develop serologically proved rubella to see whether asymptomatic infection after the administration of immunoglobulin was harmful to the fetus. McDonald and Peckham (1967), in a study of 30,000 women exposed to rubella in early pregnancy, showed that the clinical attack rate was reduced by immunoglobulin. If clinical rubella occurred after the administration of immunoglobulin a high proportion of the children suffered defects, the most common of which was deafness. When the children of the mothers who had shown no clinical evidence of infection were followed up the incidence of rubella-type defects was found to be no higher than would be expected in a normal population, thus suggesting that subclinical rubella, if it had occurred, was not harmful to the fetus. This was particularly noteworthy as the children most at risk-namely, the home contacts exposed in the first 12 weeks of pregnancy-were followed up to the age of 2 years, when most defects such as deafness should have become apparent. That study was carried out before the development of serological tests; nevertheless, it must be assumed that in view of the extensive nature of the 1962 rubella epidemic and the serological confirmation of congenital 
rubella infection in the offspring of a high proportion of women who had been exposed to clinical disease (Peckham, 1972) a similar proportion of subclinical cases would have been included in the "non-rubella" group.

The findings described here support the observations of McDonald and Peckham (1967), and it seems that patients with serologically diagnosed rubella in whom no rash had occurred after immunoglobulin had been given were not at the same risk as those exposed to clinical disease. It is possible that some of the subclinical attacks were, in fact, reinfections and that the methods of serological testing used in this large-scale trial were not adequate to detect extremely low levels of rubella antibody resulting from infection earlier in life. On the other hand, modification of the disease process by immunoglobulin may have prevented placental infection and subsequent fetal damage.

Brown (1968) found that immunoglobulin did not reduce the incidence of rubella in susceptible women but suppressed the clinical manifestations of the disease. He found that damage to the fetus after maternal infection in the first trimester occurred in only one of the 14 pregnancies where immunoglobulin was administered compared with four out of 27 pregnancies of uninoculated women, 20 of whom were infected after the first trimester.

The distinction between subclinical primary infection and reinfection may be extremely difficult to make by measurement of serum H.I. or neutralizing rubella antibody in paired samples of sera. In cases of reinfection there is usually a rise in rubella H.I. antibody depending on the initial titre, but this is shown by a rise in the IgG and not in the IgM as it is in a primary infection. This distinction is important as reinfection is not known to be associated with congenital rubella. Boué (1971) examined the problem of reinfection by following up the offspring of three women exposed to rubella in pregnancy in whom there was a significant rise in total rubella H.I. antibody which was confined to the IgG fraction. He found that the children were without defects and showed no serological or virological evidence of intrauterine rubella infection.

In the present study $53 \%$ of children exposed to clinical rubella in utero showed evidence of intrauterine infection and there was a close correlation between the presence of rubella antibody and a defect. These findings were similar to those of a previous study, in which at examination between 1 and 4 years of age of 218 children exposed to clinical rubella in pregnancy after the use of immunoglobulin $54 \%$ were shown to have detectable rubella antibody (Peckham, 1972). In that study, however, the diagnosis of rubella in the mother had been made on clinical grounds alone.

The limitations to the use of immunoglobulin are many. A high proportion of women will be unaware that they are pregnant in the early months when the fetus is at greatest risk and so will not seek advice after contact with rubella. Secondly, the primary contact may not be known as rubella is often subclinical. The interval between contact and administration of immunoglobulin is important as is also the variation of antibody titre in different batches of immunoglobulin. For these reasons immunoglobulin is bound to be of limited usefulness in the prevention of rubella defects. Nevertheless, until the effect of mass vaccination is fully evaluated large doses of immunoglobulin of high titre antibody could be used for susceptible women in contact with rubella in early pregnancy because there will always be a number of pregnant women exposed to rubella who do not wish to have the pregnancy terminated. In these cases immunoglobulin may be beneficial but it is essential that if it is used serological testing must be done to determine whether the pregnant woman has escaped infection.

I should like to thank the members of the working party on rubella for permission to examine the children; Dr. E. Vandevelde for testing some of the sera; Professor J. A. Dudgeon, Dr. W. C. Marshall, and Dr. T. Pollock for their constant interest, help, and advice; children's general practitioners for their co-operation; the paediatricians who kindly examined some of the children; and Mr. G. Hawkins for his technical help.

\section{References}

Boué, A., Nicolas, A., and Montagnum, B. (1971). Lancet, 1, 1251.

Brown, G. C. (1968). Proceedings of the Society for Experimental Biology and Medicine, 127, 340.

Dudgeon, J. A., et al. (1971). The Practitioner, 207. 782.

McDonald, J. C., and Peckham, C. S. (1967). British Medical fournal, 3, 633. Marshall, W. C., Peckham, C. S., Darby, C. P., Dudgeon, J. A., and Hawkins, G. T. (1971). The Practitioner, 207, 632 .

Peckham, C. S. (1972). Archives of Disease in Childhood, 47, 571.

Public Health Laboratory Service Working Party on Rubella (1970). British Medical fournal, 2, 497.

\title{
Amitriptyline and Imipramine Poisoning in Children
}

\author{
K. M. GOEL, R. A. SHANKS
}

British Medical fournal, 1974, 1, 261-263

\section{Summary}

The increasing number of children admitted to this hospital with poisoning by tricyclic antidepressants is causing concern. Of 60 children admitted between January 1966 and July 1973, half were admitted in the last 18 months. In $60 \%$ of these patients the tricyclic com-

Royal Hospital for Sick Children, Glasgow G3 8SJ

K. M. GOEL, M.D., M.R.C.P., Senior Registrar in Paediatrics R. A. SHANKS, M.D., F.R.C.P., Consultant Paediatrician

pounds had been prescribed for nocturnal enuresis. One child aged 2 years and 4 months died of imipramine poisoning. It is imperative that all children with poisoning by tricyclic compounds, irrespective of the dosage, are admitted to hospital for continuous cardiac monitoring. Cardiac arrhythmias induced in children by amitriptyline and imipramine are prominent and dangerous.

In the earlier years of this survey the antidepressants taken by children had usually been prescribed for adults, but recently they have been increasingly prescribed as a treatment for enuresis in children themselves. Medicine for a trivial complaint is unlikely to be regarded by parents as potentially dangerous and practitioners should therefore warn them accordingly; if, indeed, the transient efiect of these potentially dangerous drugs upon the average case of bed-wetting in childhood can be justified. 